\title{
Papers
}

\section{$\beta$ lactam monotherapy versus $\beta$ lactam-aminoglycoside combination therapy for fever with neutropenia: systematic review and meta-analysis}

Mical Paul, Karla Soares-Weiser, Leonard Leibovici

\author{
Abstract \\ Objective To compare the effectiveness of $\beta$ lactam \\ monotherapy versus $\beta$ lactam-aminoglycoside \\ combination therapy in the treatment of patients with \\ fever and neutropenia. \\ Data sources Medline, Embase, Lilacs, the Cochrane \\ Library, and conference proceedings to 2002. \\ References of included studies and contact with \\ authors. No restrictions on language, year of \\ publication, or publication status. \\ Study selection All randomised trials of $\beta$ lactam \\ monotherapy compared with $\beta$ lactam- \\ aminoglycoside combination therapy as \\ empirical treatment for patients with fever and \\ neutropenia. \\ Data selection Two reviewers independently applied \\ selection criteria, performed quality assessment, and \\ extracted data. An intention to treat approach was \\ used. Relative risks were pooled with the random \\ effect model. \\ Main outcome measure All cause fatality. \\ Results Forty seven trials with 7807 patients met \\ inclusion criteria. Nine trials compared the same \\ $\beta$ lactam. There was no significant difference in all \\ cause fatality (relative risk $0.85,95 \%$ confidence \\ interval 0.72 to 1.02 ). For success of treatment there \\ was a significant advantage with monotherapy $(0.92$, \\ 0.85 to 0.99 ), though there was considerable \\ heterogeneity among trials. There was no significant \\ difference between monotherapy and combination \\ treatment in trials that compared the same $\beta$ lactam, \\ whereas there was major advantage with \\ monotherapy in trials that compared different $\beta$ \\ lactams $(0.87,0.80$ to 0.93$)$. Rates of \\ superinfection were similar. Adverse events, including \\ those associated with severe morbidity, were \\ significantly more common in the combination \\ treatment group. Detected flaws in methods did not \\ affect results. \\ Conclusions For patients with fever and neutropenia \\ there is no clinical advantage in treatment with \\ $\beta$ lactam-aminoglycoside combination therapy. \\ Broad spectrum $\beta$ lactams as monotherapy should \\ be regarded as the standard of care for such \\ patients.
}

\section{Introduction}

Patients with fever and neutropenia can be treated with a single $\beta$ lactam (third or fourth generation antipseudomonal cephalosporins or carbapenems) or $\beta$ lactam-aminoglycoside combination therapy. ${ }^{1}$ So far studies that have compared monotherapy with combination therapy have not been large enough to compare survival. Comparative data regarding high risk subgroups are needed, ${ }^{2}{ }^{3}$ and thus far conclusions regarding superinfections are contradictory. ${ }^{45}$

We performed a systematic review and metaanalysis of $\beta$ lactam monotherapy and $\beta$ lactamaminoglycoside combination therapy to compare all cause fatality.

\section{Methods}

We searched Medline, Embase, Lilacs, the Cochrane Library, and the Interscience Conference on Antimicrobial Agents and Chemotherapy up to the year 2002. The terms "neutropenia" and similar and "aminoglycoside" or specific aminoglycosides were crossed. References of all included trials and reviews identified were scanned for additional studies. We put no restrictions on language, year of publication, or publication status.

We included all randomised trials that compared treatment with any $\beta$ lactam alone with any combination of a $\beta$ lactam and an aminoglycoside, for the empirical treatment of patients with fever and neutropenia. We excluded studies with a dropout rate above $30 \%$, unless intention to treat analysis was carried out for mortality or failure outcomes.

Two reviewers independently applied inclusion and exclusion criteria and extracted the data. Allocation generation and concealment, ${ }^{67}$ blinding, method of analysis (intention to treat or per protocol), number of dropouts, randomisation unit (patient or episode), follow up, and publication status were recorded. Authors of all included trials were contacted for complementary information.

Our primary outcome was all cause fatality at the end of follow up and up to 30 days after treatment was stopped. Our secondary outcomes included failure of treatment (defined as death, persistence, recurrence, or worsening of presenting infection, and any modifica-
Rabin Medical

Centre, Beilinson

Campus, Infectious

Diseases Unit and

Department of

Medicine E,

Petah-Tiqva 49100,

Israel

Mical Paul

Rabin Medical

Centre, Beilinson

Campus,

Department of

Medicine E, Internal

Medicine E,

Petah-Tiqva

Karla Soares-Weiser coordinator of clinic

Leonard Leibovici associate professor

Correspondence to:

M Paul

mica@zahav.net.il

bmj.com 2003;326:1111

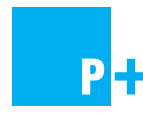

A list of all identified studies can be found on bmj.com 
tions to the assigned antibiotic treatment); bacterial and fungal superinfections; colonisation; and adverse events. Predefined subgroups were patients with haematological cancer, severe neutropenia $\left(<100 / \mathrm{mm}^{3}\right)$, bacteraemia, documented infections, and Pseudomonas aeruginosa infections.

We pooled relative risks using a random effect model and compared them with a fixed effect model. ${ }^{8}$ Analyses were performed by intention to treat, unless data were given only for those patients who could be evaluated. We assessed heterogeneity with $\chi^{2}$ test. As we anticipated heterogeneity between studies comparing the same $\beta$ lactam and studies comparing different $\beta$ lactams ${ }^{9}$ we separated analysis of these trials. The effect of measures of quality was examined through sensitivity analysis. A funnel plot of log of the relative risk against the sample size was examined to estimate potential selection bias (such as publication bias) and to assess whether effect estimates were associated with study size. We used the inverse of the variance to calculate pooled means for all studies and tested correlations for significance with a non-parametric test (Spearman).

\section{Results}

We evaluated 72 eligible randomised trials (see bmj.com for full list of references) and included 47 in the review (fig 1). The trials included 7807 patients and 8803 febrile episodes (28 to 1034 patients per trial) and took place from 1981 to 2000. Nine trials compared the same $\beta$ lactam, while all other trials compared one $\beta$ lactam with a different, narrower spectrum $\beta$ lactam combined with an aminoglycoside.

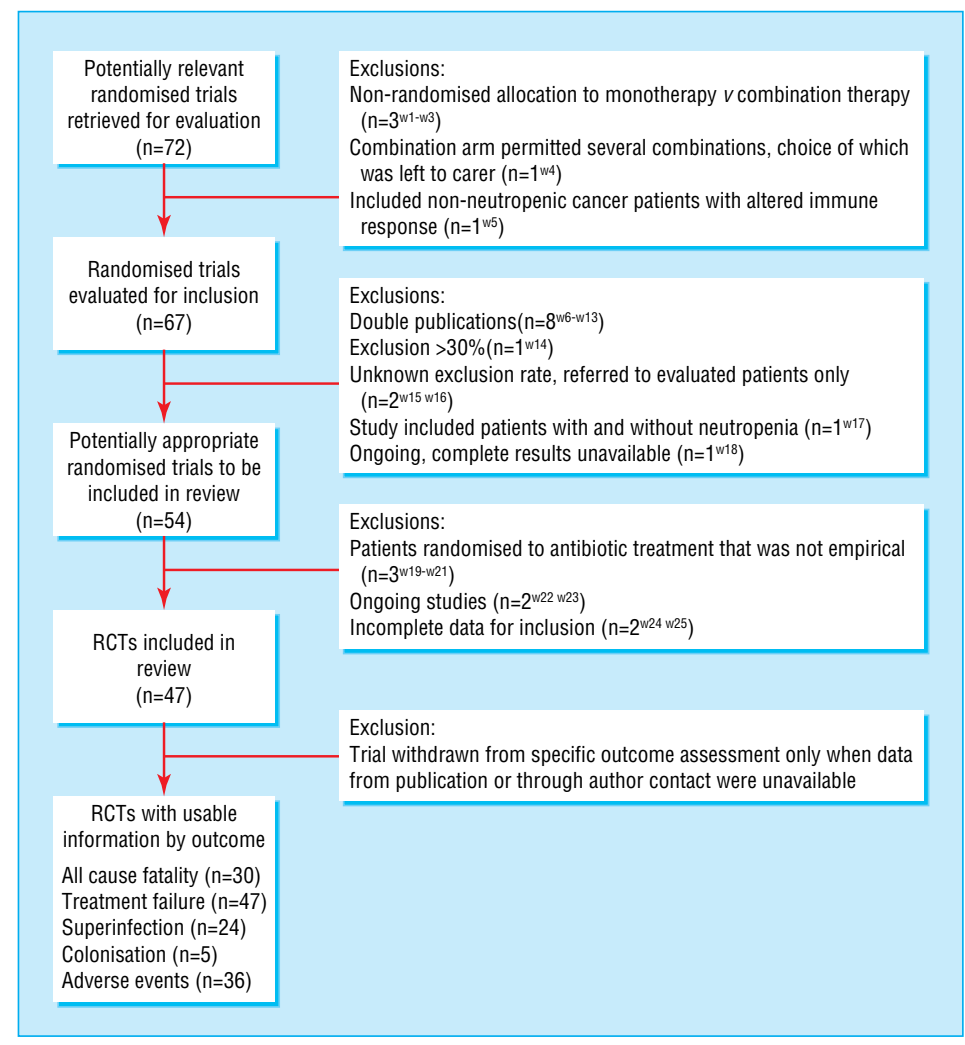

Fig 1 Trials identified for study and exclusions
In 21 trials $(45 \%)$ randomisation procedures were adequate, and eight (17\%) were blinded (table 1). Intention to treat analysis for failure was possible in 17 of the 47 trials and for fatality in 18 of 30 trials. The median dropout rate was $9 \%$. In 31 trials episodes of fever were the unit of randomisation. and the number of participating patients was given in $25(81 \%)$, and the episode to patient ratio varied from 1.03 to 1.63 among trials.

Many patients $(89 \%)$ had haematological malignancies, and $61 \%$ had severe neutropenia $(<100 /$ $\mathrm{mm}^{3}$ ) on admission. Eight trials included children, five being restricted to children below 16 years. The adjusted mean percentage of documented infections was $56 \%$, with rates varying from $24 \%$ to $94 \%$. Bacteraemia was present in $24 \%$ of patients (4-57\%). P aeruginosa was isolated in less than 2\% (0-13\%) of included patients, constituting $15 \%(0-44 \%)$ of all documented Gram negative isolates. Gram positive bacteria were identified more commonly than Gram negative bacteria in two third of the trials.

Eighteen studies compared resistance rates of pathogens isolated on admission in the two treatment arms. In 12 of these studies, resistance to the $\beta$ lactam in the combination therapy was more common than resistance to the $\beta$ lactam in monotherapy (when these differed). Resistance was similar in two studies. However, when we considered the combined coverage offered by the aminoglycoside and the $\beta$ lactam of the combination arm, resistance rates were similar for both arms.

\section{All cause fatality}

The average all cause fatality was $6.2 \%$, with a decline in fatality correlating with advancing year of the study $\left(r_{s}=-0.43, \mathrm{P}=0.03\right)$. Comparative fatality data were obtained for 30 trials (fig 2). When all studies were combined there was no significant difference between monotherapy and combination therapy (relative risk $0.85,95 \%$ confidence interval 0.72 to 1.02 ). Five trials compared the same $\beta$ lactam (0.73, 0.49 to 1.08 ), and 24 studies compared different $\beta$ lactams $(0.89,0.73$ to 1.08). No significant differences in fatality were present among all subgroups tested (table 2).

\section{Treatment failure}

When we combined all studies we found an advantage with monotherapy $(0.92,0.85$ to $0.99,47$ trials), but there was significant heterogeneity among trials $\left(\chi^{2}\right.$ 73.28, $\mathrm{df}=46, \mathrm{P}=0.0064$, fig 3 ). There was no significant difference between monotherapy and combination therapy in trials that compared the same $\beta$ lactam in both arms (nine trials, 1.12, 0.96 to 1.29), whereas there was a significant benefit with monotherapy in trials that compared different $\beta$ lactams $(0.87,0.80$ to 0.93 , 38 trials). Among subgroups, there was a significant advantage with monotherapy for patients with documented infections and those with haematological malignancy. No correlation was observed between treatment failure and fatality in the studies $(r=0.03$, $\mathrm{P}=0.9$, 29 trials). Rates of treatment failures did not decline in recent years nor was the variance between studies reduced.

\section{Superinfections and colonisation}

Superinfections developed with similar frequencies after combination or monotherapy $(0.97,0.82$ to 1.14 , 
Table 1 Characteristics of included studies

\begin{tabular}{|c|c|c|c|c|c|c|c|c|c|}
\hline & Monotherapy & Combination therapy & $\begin{array}{l}\text { Patients/ } \\
\text { episodes }\end{array}$ & $\begin{array}{c}\text { Neutropenia } \\
\left(/ \mathrm{mm}^{3}\right)\end{array}$ & $\begin{array}{l}\text { Haematological } \\
\text { cancer (\%) }\end{array}$ & $\begin{array}{l}\text { Documented } \\
\text { infection (\%) }\end{array}$ & $\begin{array}{c}\text { Bacteraemia } \\
(\%)\end{array}$ & $\begin{array}{c}\text { Allocation } \\
\text { concealment }\end{array}$ & $\begin{array}{l}\text { Allocation } \\
\text { generation } \\
\text { (blinding) }\end{array}$ \\
\hline \multicolumn{10}{|l|}{ Adults } \\
\hline Akova 1999§²6 & Meropenem & Ceftazidime-amikacin OD & $\mathrm{NS} / 83$ & 500 & 78 & 63.9 & 16.9 & A & A \\
\hline Alanis $1983^{\mathrm{w} 27}$ & Moxalactam & Nafcillin-tobramycin & $86 / 108$ & 1000 & 85 & 73.1 & NS & A & A \\
\hline Au $1994^{228}$ & Imipenem & Ceftriaxone-gentamicin & 56 & 1000 & NS & 28 & 14 & $B$ & B \\
\hline Behre $1998 \S^{\text {w29 }}$ & Meropenem & Ceftazidime-amikacin & $71 / 78$ & 500 & 55 & 41 & 28.2 & A & B \\
\hline Bezwoda $1985^{w 30}$ & Moxalactam & Cephradine-tobramycin & 63 & 1000 & 65 & 100 & 30 & $B$ & $B$ \\
\hline Cornelissen $1992^{\text {w31 }}$ & Imipenem & $\begin{array}{l}\text { Cefuroxime or } \\
\text { cephalotin-gentamicin }\end{array}$ & $93 / 100$ & 500 & 75 & 81.9 & 30.9 & B & B \\
\hline De la Camara $1997 \S^{\text {w32 }}$ & Meropenem & Ceftazidime-amikacin & 103 & 500 & 100 & 54.8 & 44.1 & A & A \\
\hline De Pauw $1983^{\text {vi33 }}$ & Ceftazidime & Cefotaxime-gentamicin & 87 & 1000 & 100 & NS & NS & $B$ & B \\
\hline De Pauw 1994\$"34 & Ceftazidime & Piperacillin-tobramycin & $1012 / 1086$ & 500 & 83 & 58.7 & 33.5 & A & A \\
\hline Del Favero 200w35 & $\begin{array}{l}\text { Piperacillin/ } \\
\text { tazobactam }\end{array}$ & $\begin{array}{l}\text { Piperacillin/ } \\
\text { tazobactam-amikacin }\end{array}$ & 760 & 500 & 81 & 49.2 & 37.8 & A & $A(D B)$ \\
\hline Dincol 1998§ & Imipenem & $\begin{array}{l}\text { Cefoperazone/ } \\
\text { sulbactam-amikacin OD }\end{array}$ & $97 / 150$ & 500 & 43 & 73.3 & 10 & B & A \\
\hline Doyen $1983 \ddagger^{w / 37}$ & Ceftazidime & Ceftazidime-amikacin & $83 / 104$ & 500 & 100 & 93.8 & 41.2 & $B$ & B \\
\hline Erjavec 1994 & Imipenem & Cefuroxime-tobramycin & $127 / 179$ & 500 & 100 & 54.5 & & $B$ & B \\
\hline Gibson $1989^{\text {m39 }}$ & Ceftazidime & Azlocillin- amikacin & 102 & 1000 & 100 & & 24.5 & A & A \\
\hline Glasmacher 1999 $\neq^{\text {ma0 }}$ & $\begin{array}{l}\text { Piperacillin/ } \\
\text { tazobactam }\end{array}$ & Ceftriaxone-gentamycin OD & $130 / 212$ & 500 & 100 & 51.9 & 19.1 & A & A \\
\hline Gribble $1983^{\text {wat }}$ & Piperacillin & Carbenicillin-gentamicin & $\mathrm{NS} / 30$ & 1000 & NS & NS & NS & B & A \\
\hline Hansen $1986^{\text {w42 }}$ & Latamoxef & Carbanicillin-gentamicin & $\mathrm{NS} / 40$ & 1500 & 0 & NS & 12.1 & B & B \\
\hline Hess $1998^{\text {mat3 }}$ & $\begin{array}{l}\text { Piperacillin/ } \\
\text { tazobactam }\end{array}$ & Ceftazidime-amikacin OD & $83 / 107$ & 500 & 67 & 80.4 & 36.4 & A & A \\
\hline 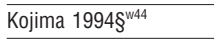 & Imipenem & Imipenem-amikacin & $60 / 70$ & 1000 & 0 & 67 & 7.5 & A & $B$ \\
\hline Leyland $1992^{\text {vit5 }}$ & Imipenem & Piperacillin-gentamicin & $234 / 312$ & 1000 & 100 & 44 & 33 & A & B (SB) \\
\hline 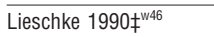 & Imipenem & Piperacillin-tobramycin & $150 / 182$ & 1000 & 55 & 26.9 & 16.5 & A & B \\
\hline Liu 1989"4/77 & Imipenem & $\begin{array}{l}\text { Ceftriaxone-amikacin or } \\
\text { ceftazidime-amikacin }\end{array}$ & 28 & 500 & 67 & 55.6 & 23.3 & B & B \\
\hline Marie $1991^{148}$ & Ceftazidime & Ceftazidime-amikacin & NS/146 & 500 & NS & NS & NS & A & A \\
\hline Matsui $1991 \S^{\text {w49 }}$ & Imipenem & Moxalactam-tobramycin & $98 / 101$ & 1000 & 0 & 100 & 4 & A & $A(S B)$ \\
\hline Norrby $19878^{\text {w50 }}$ & Imipenem & Piperacillin-amikacin & 210 & 1000 & 93 & 57.1 & 14.3 & A & B \\
\hline Novakova 1990w51 & Ceftazidime & Piperacillin-amikacin & $83 / 90$ & 500 & 100 & NS & 30 & A & A \\
\hline Novakova $1991^{152}$ & Ceftazidime & Ceftazidime-amikacin & $82 / 90$ & 1000 & 100 & 100 & 23.3 & A & A \\
\hline 0zyilkan 1999sw53 & Imipenem & $\begin{array}{l}\text { Cefoperazone/ } \\
\text { sulbactam-amikacin }\end{array}$ & 30 & 1000 & 93 & 70 & 56.7 & A & $A(D B)$ \\
\hline Pegram 1984 $\ddagger^{w 54}$ & Moxalactam & Ticarcillin-tobramycin & NS/140 & 1000 & NS & 70 & 32.1 & $B$ & $B$ \\
\hline Pellegrin $1988^{w 55}$ & Ceftazidime & Cefotaxime-tobramycin & 157 & 500 & 100 & 77.7 & 27.4 & $B$ & A \\
\hline Perez $1995^{w 56}$ & Imipenem & Ceftazidime-amikacin & $52 / 60$ & 500 & 88 & 68.3 & 48.3 & B & A \\
\hline Piccart 1984 ${ }^{\text {w57 }}$ & Cefoperazone & Cefoperazone-amikacin & 49 & 1000 & 55 & 67.3 & 55.1 & $B$ & $B$ \\
\hline Pickard 1982‡ ${ }^{w 58}$ & Moxalactam & Ticarcillin-tobramycin & $\mathrm{NS} / 80$ & 1000 & 54 & 72.5 & 45 & A & A \\
\hline Piguet $1988^{m 59}$ & Ceftazidime & Cefotaxime-amikacin & NS/174 & 500 & 100 & 56 & 30.2 & $B$ & B \\
\hline Rodjer 1987w60 & Ceftazidime & Cefuroxime-tobramycin & $52 / 61$ & 1000 & 90 & 44.8 & 37.9 & $B$ & B \\
\hline Rolston $1992^{\text {w61 }}$ & $\begin{array}{l}\text { Ceftazidime } \\
\text { imipenem }\end{array}$ & $\begin{array}{l}\text { Ceftazidime-amikacin } \\
\text { Imipenem-amikacin }\end{array}$ & NS/908 & 1000 & 67 & 46.5 & & B & $\mathrm{A}(\mathrm{SB})$ \\
\hline Tamura 2002 ${ }^{\text {w62 }}$ & $\begin{array}{l}\text { Cefepime/ } \\
\text { carbapenem }\end{array}$ & Cefepime-aminoglycoside & 165 & 1000 & 89 & 24 & 8.5 & B & B \\
\hline Wade $1987 \rrbracket^{\mathrm{w}}{ }^{3}$ & Imipenem & Piperacillin-amikacin & $\mathrm{NS} / 460$ & 1000 & NS & 64.6 & 14.3 & B & $\mathrm{B}(\mathrm{DB})$ \\
\hline Yamamura 1997§ ${ }^{\text {w64 }}$ & Cefepime & Piperacillin-gentamicin & 111 & 1000 & 65 & 49.5 & 23.4 & A & A \\
\hline \multicolumn{10}{|l|}{ Adults and children } \\
\hline Borbolla 2001w65 & Cefepime & Ceftriaxone-amikacin OD & 40 & 500 & 100 & & 15 & B & B \\
\hline Cometta 1996"w66 & Meropenem & Ceftazidime-amikacin OD & 1034 & 1000 & 72 & 47.5 & 22 & A & $A(S B)$ \\
\hline Kinsey $1990^{\text {w67 }}$ & Ceftazidime & Ceftazidime-gentamicin & 139/205 & 500 & 100 & & 46.2 & B & $B$ \\
\hline \multicolumn{10}{|l|}{ Children } \\
\hline Agaoglu $20018^{\text {w68 }}$ & Meropenem & $\begin{array}{l}\text { Cefepime-netilmicin or } \\
\text { ceftazidime-amikacin }\end{array}$ & $82 / 87$ & 1000 & 85 & 39.1 & 26.4 & B & B \\
\hline Duzova $20018^{\text {w69 }}$ & Meropenem & Piperacillin-amikacin OD & NS/90 & 500 & 62 & NS & 23.3 & B & B (SB) \\
\hline Jacobs $1993^{\text {w70 }}$ & Ceftazidime & Ceftazidime-tobramycin & $92 / 107$ & 500 & NS & 32.2 & 23.3 & $B$ & B \\
\hline Morgan $1983^{\text {w71 }}$ & Ceftazidime & Azlocillin-tobramycin & $34 / 50$ & 1000 & 68 & 44 & 28 & B & B \\
\hline Smith $1990 \S^{\text {w72 }}$ & Ceftriaxone & Azlocillin-netilmicin & $63 / 100$ & 500 & 87 & NS & 34 & $B$ & $B$ \\
\hline
\end{tabular}

$\mathrm{OD}=$ once daily aminoglycoside treatment; $\mathrm{NS}=$ not stated; $\mathrm{SB}=$ single blind; $\mathrm{DB}=$ double blind.

${ }^{*} A=$ adequate (central randomisation, inaccessible computer randomisation, sealed envelopes); $B=$ uncertain (no details concerning randomisation procedure, or methods unclear) $C=$ inadequate (alternation, case record numbers, dates of birth or day of the week, open list of random numbers).

$\dagger A=$ any method resulting in adequate randomisation; $B=$ uncertain procedure.

†Conference proceedings, additional data/manuscripts obtained from authors.

$\S$ Complementary data from authors included in review.

ๆConference proceeding describes trial design, outcomes obtained from subsequent authors' reviews. ${ }^{\text {w72 }}$ w73 


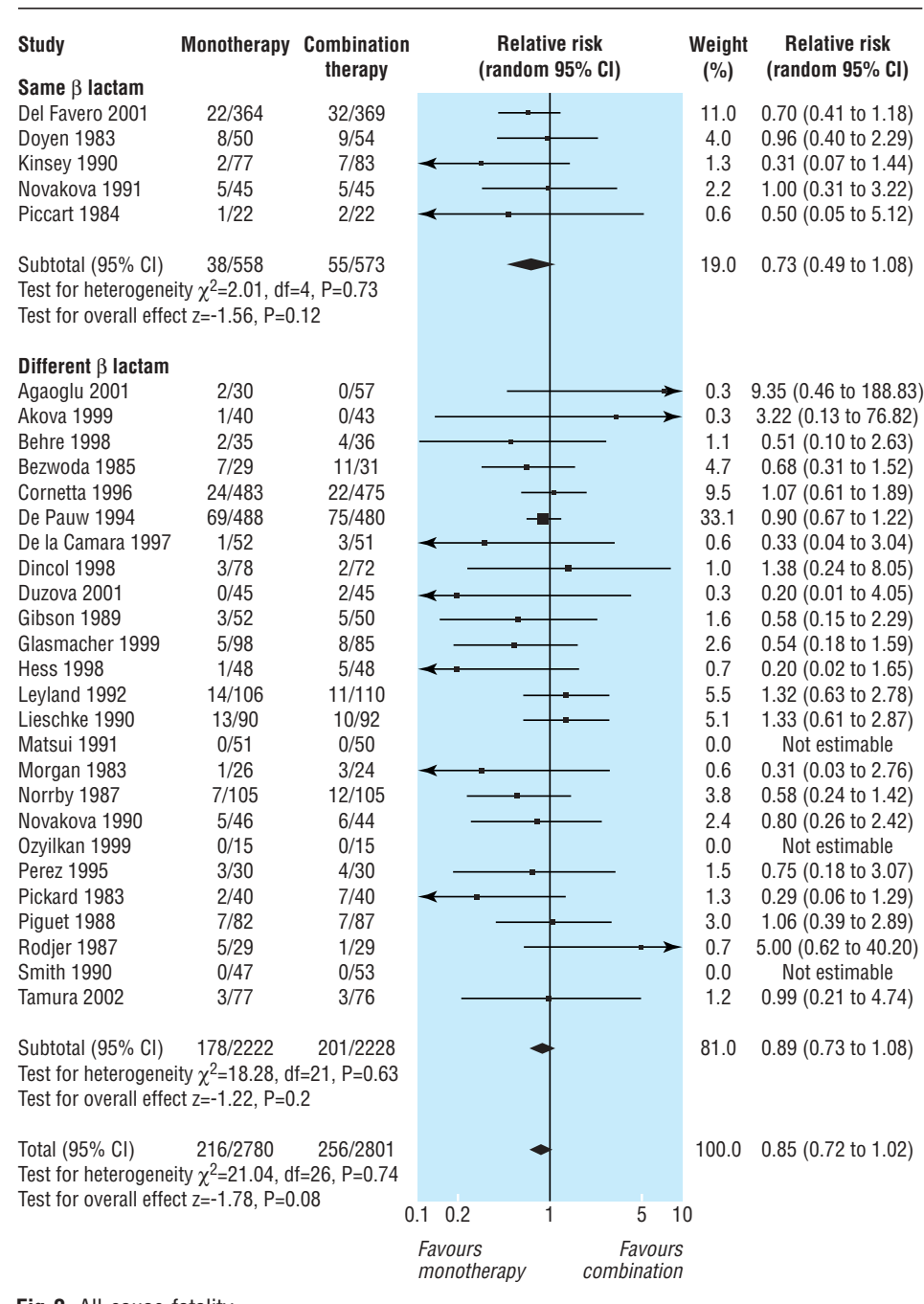

Fig 2 All cause fatality adverse events occurred was more common in the combination group $(0.57,0.36$ to 0.91$)$.

Compared with smaller trials, larger trials had relative risks closer to equivalence. When we looked at treatment failure, in trials that compared different $\beta$ lactams and in which the number of randomised patients was below the median, monotherapy showed a highly significant advantage $(0.73,0.64$ to 0.84$)$, while larger studies showed no such advantage ( $0.94,0.89$ to $1.00, \mathrm{P}=0.025$ for the difference). The corresponding funnel plot for treatment failure generated a nearly symmetrical "funnel distribution." Sensitivity analyses by all quality measures did not reveal any effect on our results (fig 7 ). ${ }^{10}$

\section{Discussion}

Our results support the use of broad spectrum $\beta$ lactam monotherapy in the empirical treatment of patients with fever and neutropenia. Most studies in our meta-analysis compared a new broad spectrum $\beta$ lactam (carbapenem, ceftazidime, cefepime, piperacillin-tazobactam) with a combination of an "older" $\beta$ lactam (usually an ureidopenicillin or a cephalosporin drug) and an aminoglycoside. In the comparisons the advantages of monotherapy were clear: a non-significant trend toward better survival, a significant advantage in preventing treatment failures, and fewer adverse effects. Fewer trials compared one $\beta$ lactam with a combination of the same $\beta$ lactam and an aminoglycoside. In these trials there were no significant benefits and more adverse effects, including severe ones, with the combination therapy. The shift of treatment failure risk-ratio towards combination therapy in these studies translates to some 20 patients who would have to be given an additional aminoglycoside to prevent one failure, which most commonly implies merely an antibiotic modification. Superinfections occurred equally with the two regimens. These results were consistent among all subgroups tested.

Synergism, proved in vitro, is usually the major reason given for combination therapy. ${ }^{11-15}$ We found no clinical benefit associated with synergism. Combination treatment may provide broader spectrum coverage. Yet single aminoglycoside treatment, or combination treatment where pathogens are covered by the aminoglycoside alone, is inadequate. ${ }^{16-18}$ Indeed, combination therapy was less effective than monotherapy in studies that compared different $\beta$ lactams, although the spectrum of coverage was similar for both arms of these trials. Finally, combination therapy may prevent emergence of resistant pathogens. ${ }^{19}{ }^{20}$ We have

Table 2 Subgroup analysis, showing number of studies and episodes included in analysis with relative risk (RR) and $95 \%$ confidence intervals

\begin{tabular}{|c|c|c|c|c|c|c|c|c|c|}
\hline & \multicolumn{3}{|c|}{ All cause fatality } & \multicolumn{3}{|c|}{ Treatment failure (same $\beta$ lactam) } & \multicolumn{3}{|c|}{ Treatment failure (different $\beta$ lactam) } \\
\hline & Studies & Episodes & RR (95\% Cl) & Studies & Episodes & RR $(95 \%$ Cl) & Studies & Episodes & RR $(95 \% \mathrm{Cl})$ \\
\hline$\overline{\text { All }}$ & 30 & 5581 & 0.85 (0.72 to 1.02$)$ & 9 & 2178 & $1.12(0.96$ to 1.29$)$ & 38 & 5920 & $0.87(0.80$ to 0.93$)$ \\
\hline Documented infections & 12 & 1158 & $0.78(0.52$ to 1.15$)$ & 7 & 1006 & 1.05 (0.89 to 1.23$)$ & 23 & 2614 & $0.88(0.82$ to 0.96$)$ \\
\hline Bacteraemia & 11 & 583 & 0.69 (0.39 to 1.22$)$ & 5 & 384 & $1.04(0.89$ to 1.21$)$ & 18 & 1054 & 0.87 (0.74 to 1.02$)$ \\
\hline Gram negative infections & 13 & 328 & $0.67(0.35$ to 1.27$)$ & 7 & 261 & $1.50(0.80$ to 2.79$)$ & 21 & 603 & $0.68(0.50$ to 0.93$)$ \\
\hline Pseudomonas infections & 7 & 58 & 0.78 (0.24 to 2.56$)$ & 3 & 49 & $1.46(0.23$ to 9.41$)$ & 12 & 90 & $0.87(0.54$ to 1.41$)$ \\
\hline Haematological cancer & 13 & 2188 & 0.78 (0.58 to 1.06$)$ & 4 & 361 & $0.92(0.76$ to 1.12$)$ & 13 & 2287 & 0.83 (0.73 to 0.96$)$ \\
\hline Severe neutropenia & 5 & 677 & 0.66 (0.35 to 1.26$)$ & $2^{*}$ & 237 & 1.49 (1.13 to 1.97$)$ & 6 & 757 & 0.94 (0.75 to 1.18$)$ \\
\hline Adults $>16$ years & 21 & 3205 & 0.88 (0.72 to 1.08$)$ & 6 & 1173 & 1.21 (1.07 to 1.37$)$ & 25 & 3503 & 0.83 (0.75 to 0.92$)$ \\
\hline Children & 4 & 327 & 0.75 (0.08 to 7.11$)$ & $1^{*}$ & 91 & 2.74 (1.08 to 6.98$)$ & 4 & 327 & $0.94(0.64$ to 1.39$)$ \\
\hline
\end{tabular}

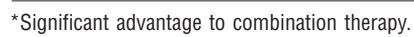


shown that superinfection rates after combination or monotherapy were similar. Information regarding colonisation was scarce. In a recent review that compared single versus combination therapy for patients with cystic fibrosis, monotherapy was associated with an increased risk of carriage of resistant $P$ aeruginosa at follow up, but duration of treatment was longer. ${ }^{9}$ As we could assess only superinfections, we can conclude that for the individual patient, during a specific episodes of infection, differences in development of resistance are clinically non-significant. Adverse events, as expected, were more common with combination therapy, and the risk was not reduced by the use of once daily aminoglycoside dosing.

The European Organisation for Research and Treatment of Cancer's EORTC IV trial is often quoted in support of combination therapy. It showed a significant advantage, for failure only, with combination therapy given for longer than 72 hours among a subgroup of patients with Gram negative bacteraemia. ${ }^{21}$ These findings are not supported by our subgroup analyses, which included 1438 episodes of bacteraemia and 864 documented Gram negative infections.

\section{Limitations of study}

We detected a sample size bias for treatment failure, with smaller studies exaggerating the beneficial effect of monotherapy. As smaller studies did not consistently differ from larger trials with respect to severity of disease, methods, or therapy, this may reflect publication bias. Most studies used febrile episodes as the unit of randomisation, allowing patients to re-enter the trial. As outcomes for re-entering patients are not independent, results may have been affected. Intention to treat analysis was possible in just over half the included trials, and adequate randomisation procedures were used in less than half of these trials. Sensitivity analyses did not detect an effect of these measures on our results.

The major caveat with respect to the interpretation of our results is the lack of data on fatality in some of the trials. Survival should be the primary outcome as it is ultimately the objective of treatment for these patients. ${ }^{22}$ Admittedly, only a small part of the variance in fatality is explained by infection. Appropriate randomisation, however, should ensure similar distribution of risk factors for death not related to infection between the study groups. Treatment failure, whether defined as modifications to treatment or delayed resolution of fever, is subjective and clinically less meaningful. Finally, for failure to have some prognostic importance it should correlate with fatality, and we have shown that in these studies a correlation did not exist.

\section{Implications for practice and research}

From our results we consider that broad spectrum monotherapy should be the standard treatment for patients with fever and neutropenia. Studies of antibiotic treatment in these patients should adhere to better standards of methods and reporting. Specifically, the unit of randomisation should be the patient not the episode. Future trials of combination treatment should be performed only to address issues where doubt still exists. Synergism should be specifically assessed by comparing the same $\beta$ lactam in both arms of the study.

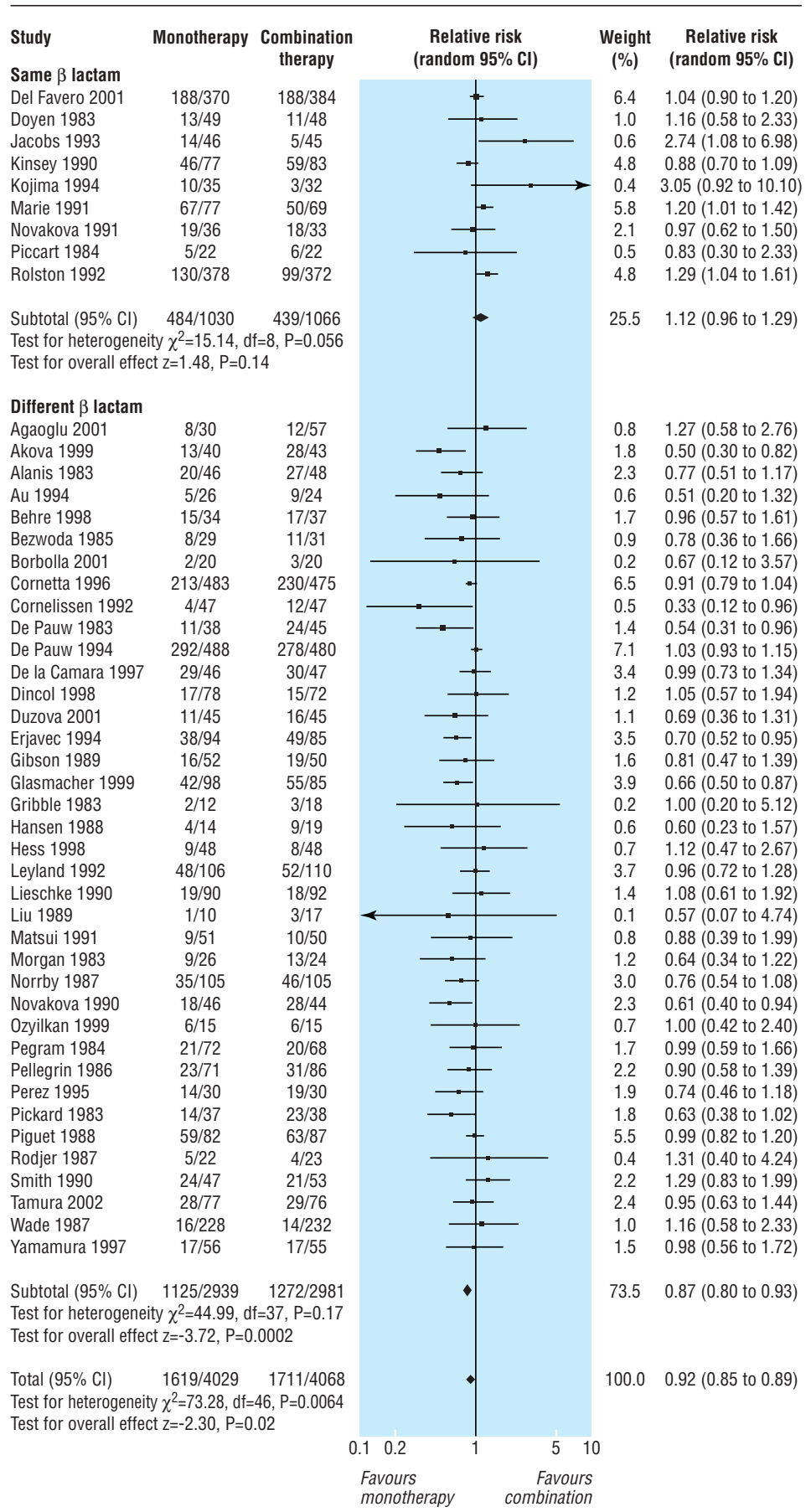

Fig 3 Treatment failure

Studies should use all cause fatality as the primary outcome. The low fatality (lower in recent years) translates into a large sample size. Survival of patients, however, is the underlying reason for empirical treatment with antibiotics for fever with neutropenia.

We thank the members of Cochrane Gynaecological Cancer Group for their thorough review process; Mandy Collingwood and Vivien Garner of the group for their advice and technical assistance; all the authors who replied to our letters and supplied available data (A M Will, J Gibson, J P Donnelly, B E De Pauw, W Pickard, C Rotstein, A Kojima, S E Kinsey, S R Norrby, K Matsui, O Ozyilkan, D Dincol, C Doyen, J L Michaux, A Duzova, L Agaoglu, Z Karakas, R F Jacobs, R de la Camara, Y Sawae, G Morgan, M Piccart, S Rehm, J P Marie, S P Pegram, and 


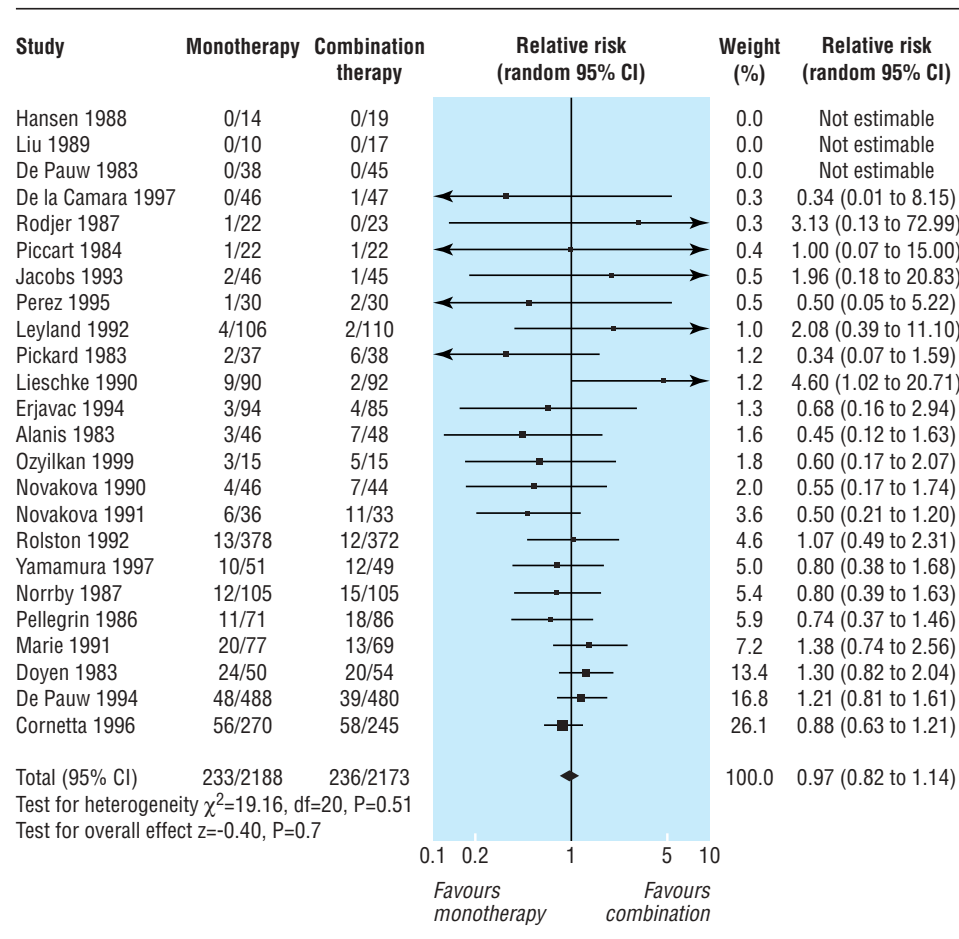

Fig 4 Bacterial superinfections sion of this review is also published in the Cochrane Library where it will be updated if further data become available. ${ }^{10}$

Contributors: MP and LL performed the search. All authors selected trials for inclusion, performed data extraction and quality assessment of the trials, and analysed the data. MP and LL contacted authors and requested missing data. All authors participated in drafting the manuscript for the Cochrane review and for the journal article. MP is guarantor for the article.

Funding: EU 5th framework grant (TREAT project, grant No 1999-11459) and the Rabin Medical Centre, Skidal Foundation. The guarantor accepts full responsibility for the conduct of the study, had access to the data, and controlled the decision to publish.

Competing interests: None declared.

1 Hughes WT, Armstrong D, Bodey GP, Bow EJ, Brown AE, Calandra T, et al. 2002 guidelines for the use of antimicrobial agents in neutropenic patients with cancer. Clin Infect Dis 2002;34:730-51.

2 Paesmans M. Risk factors assessment in febrile neutropenia. Int J Antimicrob Agents 2000; 16: 107-11.

3 Elting LS, Rubenstein EB, Rolston KV, Bodey GP. Outcomes of bacteremia in patients with cancer and neutropenia: observations from two decades of epidemiological and clinical trials. Clin Infect Dis 1997;25:247-59.

4 Pizzo PA, Hathorn JW, Hiemenz J, Browne M, Commers J, Cotton D, et al. A randomized trial comparing ceftazidime alone with combination antibiotic therapy in cancer patients with fever and neutropenia. N Engl J Med biotic therapy in
1986;315:552-8

5 Kramer BS, Ramphal R, Rand KH. Randomized comparison between two ceftazidime-containing regimens and cephalothin-gentamicincarbenicillin in febrile granulocytopenic cancer patients. Antimicrob Agents Chemother 1986;30:64-8.

6 Clarke M, Oxman AD, eds. Cochrane reviewers' handbook 4.1.4. Oxford: Update Software, 2001.

7 Schulz KF, Chalmers I, Hayes RJ, Altman DG. Empirical evidence of bias. Dimensions of methodological quality associated with estimates of treatment effects in controlled trials. JAMA 1995;273:408-12.

8 ment Simonian R, Laird N. Meta-analysis in clinical trials. Control Clin Trials 1986;7:177-88

What is already known on this topic

Cancer patients with neutropenia and fever can be treated with a single broad spectrum $\beta$ lactam antibiotic or with a combination of a $\beta$ lactam and an aminoglycoside

Many randomised trials have compared monotherapy with combination therapy for these patients, but no consensus has been reached regarding the superiority of one regimen over the other

\section{What this study adds}

There is no survival advantage with combination therapy

Broad spectrum $\beta$ lactam monotherapy is more successful than a narrower spectrum $\beta$ lactam agent combined with an aminoglycoside

Combination therapy is associated with a significantly higher rate of adverse events, mainly nephrotoxicity

S W Hansen); A Glasmacher and G J Lieschke who supplied their full unpublished manuscripts; G Keddie and B Wilks of AstraZeneca for supplying their available data; and G P Bodey for his response and comments. Partial results were presented at the 41st Interscience Conference on Antimicrobial Agents and Chemotherapy, December 2001, Chicago. A more detailed vertherapy for people with cystic fibrosis. Cochrane Database Syst Re 2003;(1):CD002007.

10 Paul M, Soares-Weiser K, Grozinsky S, Leibovici L. Beta-lactam versus beta-lactam-aminoglycoside combination therapy in cancer patients with neutropaenia. Cochrane Database Syst Rev 2003;(1):CD003038.

11 Giamarellou H, Zissis NP, Tagari G, Bouzos J. In vitro synergistic activities of aminoglycosides and new beta-lactams against multiresistant Pseudomonas aeruginosa. Antimicrob Agents Chemother 1984;25:534-6.

12 Giamarellou H. Aminoglycosides plus beta-lactams against gramnegative organisms. Evaluation of in vitro synergy and chemical interactions. Am J Med 1986;80:126-37.

13 Klastersky J, Meunier-Carpentier F, Prevost JM. Significance of antimicrobial synergism for the outcome of gram negative sepsis. Am J Med Sci 1977;273:157-67.

4 Klastersky J, Zinner SH. Synergistic combinations of antibiotics in gramnegative bacillary infections. Rev Infect Dis 1982;4:294-301.

15 Den Hollander JG, Horrevorts AM, van Goor ML, Verbrugh HA, Mouton JW. Synergism between tobramycin and ceftazidime against a resistan Pseudomonas aeruginosa strain, tested in an in vitro pharmacokinetic model. Antimicrob Agents Chemother 1997:41:95-100.

16 Leibovici L, Paul M, Poznanski O, Drucker M, Samra Z, Konigsberger H, et al. Monotherapy versus beta-lactam-aminoglycoside combination treatment for gram-negative bacteremia: a prospective, observational study. Antimicrob Agents Chemother 1997;41:1127-33.

17 Bodey GP, Middleman E, Umsawadi T, Rodriguez V. Infections in cancer patients. Results with gentamicin sulfate therapy. Cancer 1972; 29:1697-701.

18 Klastersky J, Glauser MP, Schimpff SC, Zinner SH, Gaya H. Prospective randomized comparison of three antibiotic regimens for empirical therapy of suspected bacteremic infection in febrile granulocytopenic patients. Antimicrob Agents Chemother 1986;29:263-70.

19 Mouton JW. Combination therapy as a tool to prevent emergence of bacterial resistance. Infection 1999;27:S24-8.

$20 \mathrm{Wu}$ YL, Scott EM, Po AL, Tariq VN. Ability of azlocillin and tobramycin in combination to delay or prevent resistance development in Pseudomonas aeruginosa. J Antimicrob Chemother 1999;44:389-92.

21 EORTC. Ceftazidime combined with a short or long course of amikacin for empirical therapy of gram-negative bacteremia in cancer patients with granulocytopenia. The EORTC International Antimicrobia Therapy Cooperative Group. N Engl J Med 1987;317:1692-8.

22 Schimpff S, Satterlee W, Young VM, Serpick A. Empiric therapy with carbenicillin and gentamicin for febrile patients with cancer and granulocytopenia. N Engl J Med 1971;284:1061-5.

(Accepted 20 March 2003) 


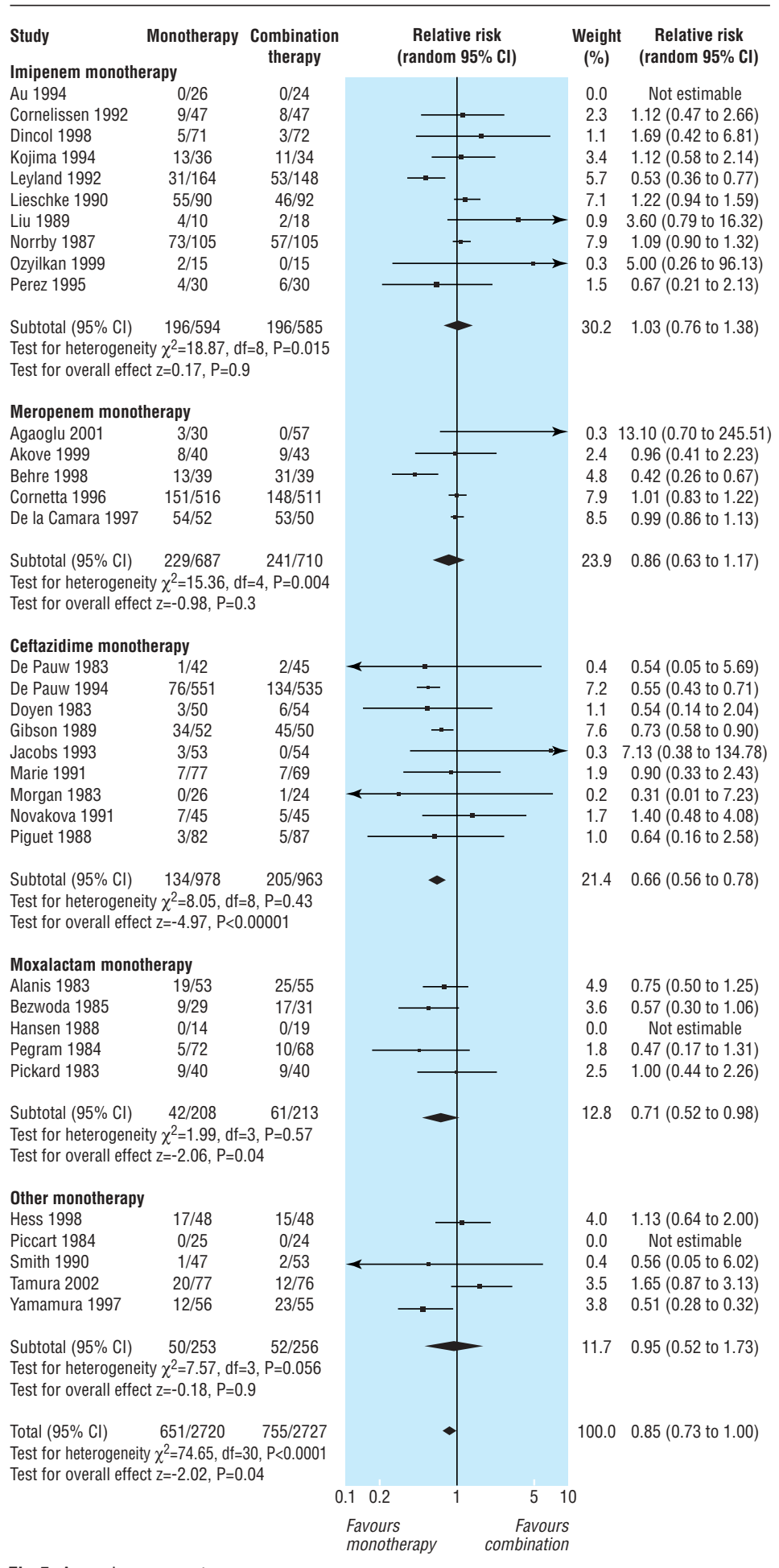

Fig 5 Any adverse event 


\section{Papers}

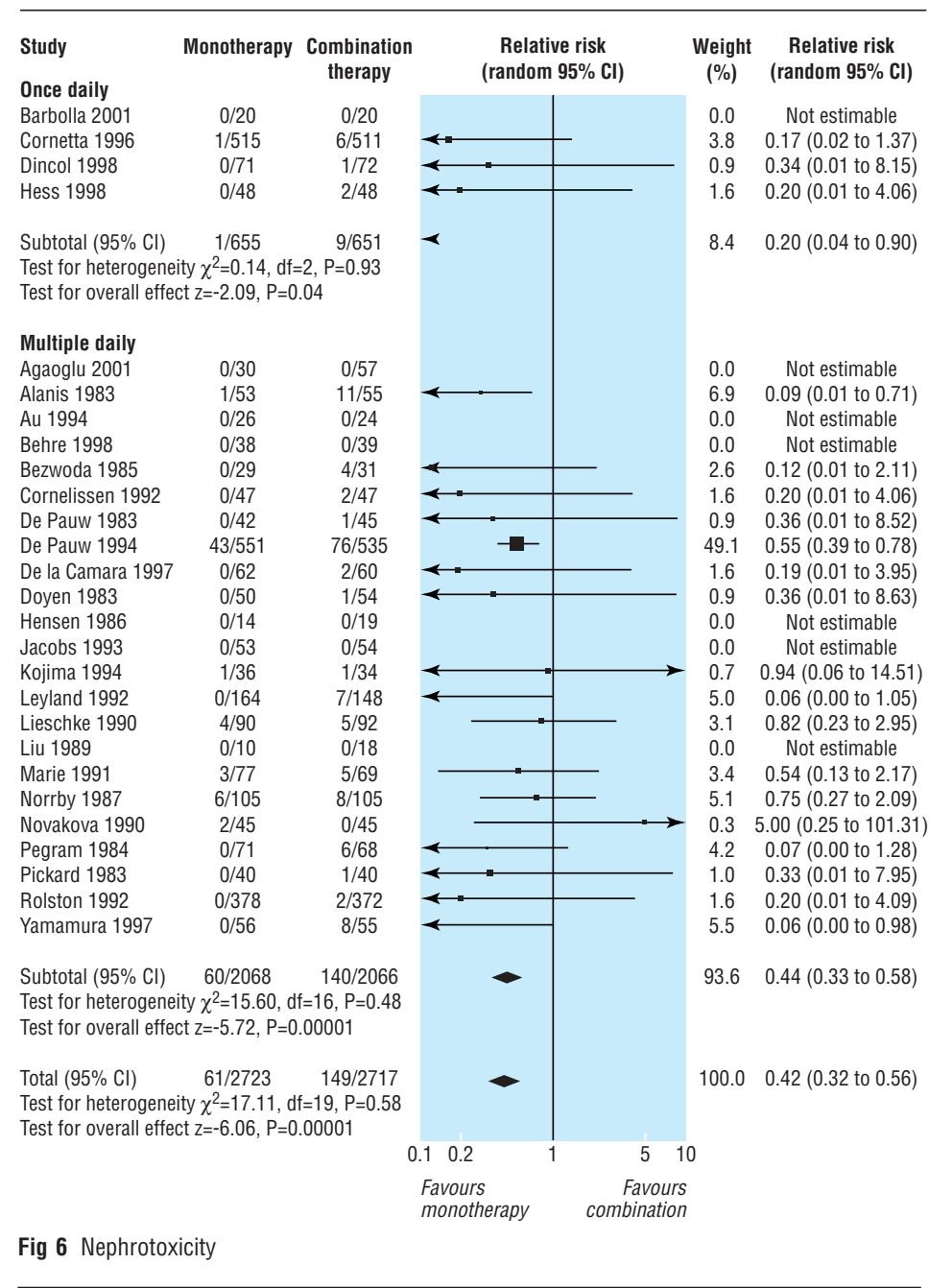




\begin{tabular}{|c|c|c|c|c|c|c|c|}
\hline & All cause fatality & & & Treatment failure & & & \\
\hline \multicolumn{8}{|c|}{ Allocation generation } \\
\hline & $A(16)$ & + & & $A(22)$ & & + & \\
\hline & B (14) & 十 & & $B(25)$ & & + & \\
\hline \multicolumn{8}{|c|}{ Allocation concealment } \\
\hline & $\mathrm{A}(17)$ & + & & $A(21)$ & & + & \\
\hline & B (13) & 1 & & $B(26)$ & & + & \\
\hline \multicolumn{8}{|l|}{ Patient-episode } \\
\hline & episode (20) & 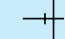 & & episode (31) & & + & \\
\hline & patient (10) & 1 & & patient (16) & & + & \\
\hline \multicolumn{8}{|l|}{ Publication status } \\
\hline & published (26) & + & & published (41) & & + & \\
\hline & unpublished (4) & , & & unpublished (6) & & +1 & \\
\hline \multicolumn{8}{|l|}{ Intention to treat } \\
\hline Per protocol (PP) & PP, D0>median (6) & 1 & & PP, D0>median (13) & & + & \\
\hline \multirow[t]{2}{*}{ Dropouts (DO) } & PP, D0<median (6) & 1 & & PP, D0<median (13) & & + & \\
\hline & Intention to treat (18) & 1 & & Intention to treat (17) $\dagger$ & & + & \\
\hline \multicolumn{8}{|l|}{ Study size } \\
\hline & above median (15) & + & & above median (24) & & & \\
\hline & below median (15) & + & & below median (23) & & + & \\
\hline & fixed effect model & + & & dropouts $=$ failure ${ }^{*}$ & & & \\
\hline \multicolumn{8}{|c|}{ Combined, random effect model } \\
\hline & 0.5 & 1 & 2 & & 0.5 & 1 & 2 \\
\hline \multicolumn{8}{|c|}{$\begin{array}{l}\text { Fig } 7 \text { Sensitivity analysis. Number in parenthesis refers to number of studies included in } \\
\text { analysis. Studies in which number of dropouts for failure analysis was not specified are not } \\
\text { included. †Analysis performed counting all dropouts as treatment failures }\end{array}$} \\
\hline
\end{tabular}

